\title{
Percorrido histórico dos Congresos de Educación Ambiental para os países Iusófonos e Galicia
}

\section{A historical reading on the Environmental Education Congresses of lusophone countries and Galicia}

Carlos Vales Vázquez. Centro de Extensión Universitaria e Divulgación Ambiental de Galicia-CEIDA (Galicia)

\section{Resumo}

Este artigo ten a súa orixe na presentación realizada polo autor nas II Xornadas Internacionais de Educación Ambiental organizadas polo Centro de Extensión Universitaria e Divulgación Ambiental de Galicia, na súa sede no Castelo de Santa Cruz en abril de 2018. Os obxectivos destas Xornadas era crear un marco de reflexión sobre a historia e os desafíos da Educación Ambiental como ferramenta para contribuír á sostibilidade e á mellora da problemática ambiental, reflexionar sobre o estado e os problemas da Educación Ambiental tanto en Galicia como noutros países con afinidades culturais e linguísticas e robustecer as relacións de cooperación internacional para aumentar a eficacia do uso da Educación Ambiental como ferramenta de intervención social. Faise un percorrido histórico dos Congresos de Educación Ambiental para os países lusófonos e Galicia, destacando a relevancia dese I Congreso de Educación Ambiental dos Países Lusófonos e Galicia, onde por primeira vez, se consigue reunir en Santiago de Compostela, a representantes de todos os países de lingua portuguesa, incluída Timor Leste. Esto foi posible gracias a implicación de moitas institucións e gobernos, de expertos de Educación Ambiental de moitos países e ao esforzo do CEIDA por incorporar a intelectuais e expertos doutras disciplinas coa intención de enriquecer o discurso de transformación social. Despois de describir a historia deste I Congreso e das súas repercusións, entre as que se destaca a de dar formación a responsables de áreas protexidas do mundo lusófono africano e do Timor Leste, continúa o percorrido ate os nosos días, onde o Congreso Lusófono ten conseguido consolidarse diante dos gobernos dos diferentes países, amosando tamén como a Rede Lusófona se converteu nun referente na Educación Ambiental neste espazo xeográfico, cultural e lingüístico. Conclúe o artigo cunha serie de recomendacións sobre a necesidade de que os Congresos Lusófonos de Educación Ambiental sexan un espazo de creación de intelixencia colectiva e de apoio á intervención socioambiental.

\section{Astract}

This paper has its origins in the presentation made by the author at the II International Conference on Environmental Education organized by the Center for University Extension and Environmental Dissemination of Galicia, at its headquarters in the Castle of Santa 
Cruz in April 2018. The objectives of these Conferences were to create a framework for reflection on the history and challenges of Environmental Education as a tool to contribute to sustainability and improvement of environmental issues, reflect on the state and problems of Environmental Education both in Galicia and in other countries with cultural and linguistic affinities and strengthen international cooperation to increase the effectiveness of the use of Environmental Education as a tool for social intervention. In this context, the author makes a historical reading of the Environmental Education Congresses for the lusophone countries and Galicia, for the need to contribute to the history of these congresses from a biographical perspective and help to understand the real origin of these congresses. The author of the article points out the relevance of this I Congress of Environmental Education of the Lusophone Countries and Galicia, where for the first time, it is possible to meet in Santiago de Compostela, representatives of all lusophone countries, including East Timor. This was made possible thanks to the involvement of many institutions and governments, Environmental Education experts from many countries and CEIDA's effort to incorporate intellectuals and experts from other disciplines with the intention of enriching the discourse of social transformation. After describing the history of this first Congress and its repercussions, including the training of the managers of protected areas in the lusophone african continent and East Timor, he continues his reading to the present day, where this Congress has managed to consolidate behind the governments of the different countries, also showing how the Lusophone Network has become a reference in Environmental Education in this geographical, cultural and linguistic area. The paper concludes with some recommendations on the need for the Lusophone Congresses on Environmental Education to be a place for the creation of collective intelligence and support for socioenvironmental intervention.

\section{Palabras chave}

educación ambiental, rede lusófona, historia, alianzas, sociedade civill.

\section{Key-words}

environmental education, lusophone network, history, alliances, civil society.

\section{Parte I}

O obxectivo primeiro deste artigo é o de contribuír á historia dos congresos lusófonos de educación ambiental desde unha perspectiva biográfica e axudar a entender a orixe da súa andadura. Hai anos que veño comentando o que para min é a construción dun falso relato sobre como os congresos de educación ambiental das comunidades de países de lingua oficial portuguesa, Galicia incluída, tentan ser reflectidos a través dunha construción falsa. Segundo esta hipótese, repetidamente exposta en público, a orixe dos congresos de educación ambiental lusófonos estaría na creación da Rede Lusófona de Educación Ambiental que, como ben informa Aidil Borges no seu artigo nesta mesma revista, tivo a súa orixe nas XII Xornadas da Asociación Portuguesa de Educación AmbientalASPEA celebradas en Ericeira, Portugal no ano 2005.

A Rede Lusófona aproveitou con bo criterio - Congreso Iberoamericano de Educación Ambiental celebrado en Joinville, Brasil, baixo os auspicios do goberno brasileiro, 
para reunións presenciais, certamente produtivas. Pero arrogarse a iniciativa da organización dos congresos lusófonos é simplemente faltar á verdade. É así porque a organización dun congreso de semellante envergadura, como foi $\circ 1^{\circ}$ Congreso Lusófono organizado desde a Galicia, require duns apoios institucionais, de recursos humáns e orzamentarios dos que a Rede Lusófona non dispoñía e que so anos despois foi quen de implementar. Pero a verdade sobre a orixe dos congresos de educación ambiental da Comunidade dos Países de Lingua oficial portuguesa é outra, e resúmese no seguinte: só coa existencia do CEIDA e co apoio do goberno do Brasil é posible explicar que os congresos lusófonos de educación ambiental sexan hoxe unha realidade consolidada.

A orixe desta historia remontase ao ano 2005 cando se celebra na cidade de Granada (Andalucía, España) o III Congreso Internacional de Educación Ambiental organizado pola Asociación Española de Educación Ambiental (Foto 1). Coincidimos nese congreso unha serie de persoas involucradas na historia da educación ambiental. Nesa reunión informal á marxe do congreso, estaban presentes Susana Calvo, coordinadora do Libro Branco da Educación Ambiental en España e Vicepresidenta da Comisión Internacional de Educación e Comunicación da Unión Internacional para a Conservación da Natureza
(UICN), Javier Benayas, da Universidade Autónoma de Madrid, José Gutiérrez, da Universidade de Granada, Pablo Meira, da Universidade de Santiago de Compostela, Araceli Serantes, da Universidade da Coruña, Javier Asin, Director do Centro de Recursos Ambientais do Goberno de Navarra-CRANA, e eu mesmo. No marco desa reunión informal, Javier Benayas plantexou a posibilidade de que, no Congreso Iberoamericano de Joinville, España presentase a súa candidatura para organizar o seguinte congreso. Opinaba que parecía unha idea razoable posto que todos os anteriores se celebraran no continente americano, en México, Venezuela, Cuba e agora o Brasil. Todos coincidimos en que era unha

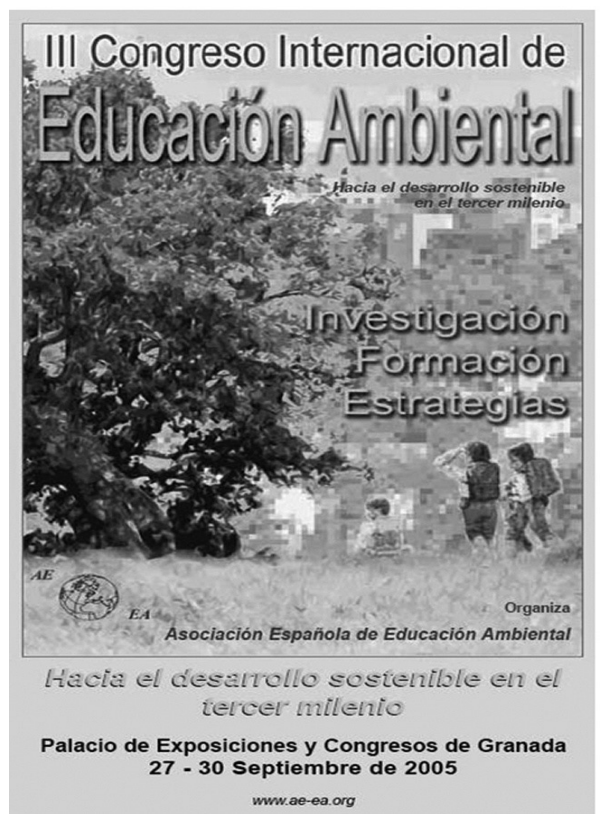

Foto 1. Cartaz do III Congreso Internacional de Educación Ambiental. 
idea interesante, pero que precisaba ir acompañada dun apoio institucional forte para garantir a cobertura dos elevados custes económicos de semellante iniciativa. Despois de valorar distintas posibilidades, ficou claro que só Galicia estaría en condicións de asumir a organización do congreso, despois de que eu aclarase que precisaba ter o compromiso explícito dos responsable do Goberno galego de que asumían a responsabilidade do éxito da iniciativa a través do seu aval institucional e, o máis importante, económico. Despois das miñas reunións co Director Xeral de Sostibilidade e Paisaxe e co Conselleiro de Medio Ambiente da Xunta de Galicia ficou claro que a proposta a levar ao Congreso de Joinville estaba institucionalmente respaldada.

A candidatura foi presentada en Joinville na reunión dos representantes oficiais dos distintos países participantes no congreso iberoamericano pola delegación española, formada por Susana Calvo, como representante do Goberno español e por min, como representante da Xunta de Galicia. Mais, dado que a delegación arxentina manifestou o seu interese en acoller o seguinte congreso iberoamericano, despois dun longo debate dentro da delegación brasileira, ante o risco de que unha candidatura española puidese ser vista en algúns sectores como un acto de prepotencia europea, Marcos Sorrentino propuxo ao plenario do congreso que se aceptase a oferta arxentina e, e isto é o novidoso, que o congreso iberoamericano apoiase a celebración dun congreso que reunise aos países de lingua oficial portuguesa, e que o anfitrión fose Galicia, proposta que foi apoiada por unanimidade.

A percepción da importancia de Galicia para a delegación brasileira non se produce por casualidade, pois a súa realidade era coñecida para moitos educadores ambientais brasileiros, así como a capacidade organizativa do CEIDA. Entre outros posibles exemplos, Marcos Sorrentino xa coñecía fisicamente a institución, a onde tiña sido convidado para participar en actividades e o responsable de impartir a palestra maxistral inaugural do congreso de Joinville, Carlos Walter Porto Gonçalves, xa tiña estado no CEIDA no ano 2002 convidado para falar da Amazonía e da traxectoria do Chico Mendes na defensa dos recursos naturais e do modo de vida dos seringueiros (CEIDA, 2006:67). (Fotos 2 e 3).

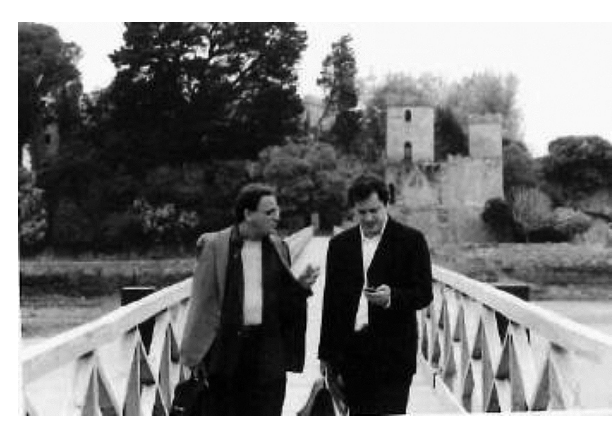

Foto 2. Carlos Walter Porto e o escritor galego Manuel Rivas no CEIDA. 


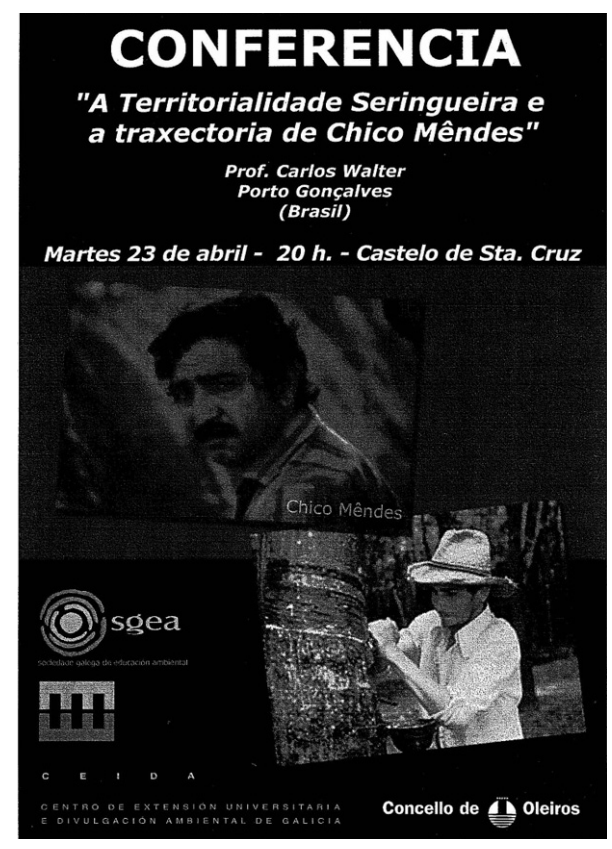

Foto 3. Cartaz da conferencia do profesor Carlos Walter Porto.

O doutor Carlos Walter Porto Gonçalves, profesor de Xeografía Humana da Universidade Federal Fluminense de Brasil e colaborador persoal de Chico Mendes falou da importancia do Amazonas como maior pulmón do planeta, sobre o mundo dos seringueiros e a súa loita políticoecolóxica e sobre a figura de Chico Mendes.

En canto á á organización do Congreso, os compromisos do Goberno do Brasil, do Goberno Español e da Xunta de Galicia, axustáronse ás expectativas. No caso do Brasil, aportando a experiencia de persoas que traballaban na súa equipa, o que posibilitou o desprazamento a Galicia de Joana de Barros Amaral, quen estivo traballando contratada polo CEIDA durante seis meses, compartillando as instalacións e os medios propios co persoal do CEIDA, identificando e facendo traballo de coordinación dos puntos focais institucionais e da sociedade civil de todos os países lusófonos. A implicación do Goberno brasileiro tamén está reflectida no feito de que practicamente un $25 \%$ dos participantes no congreso fosen brasileiros (Foto 4).
Foto 4. Países de procedencia das persoas que asistiron ao I Congreso.

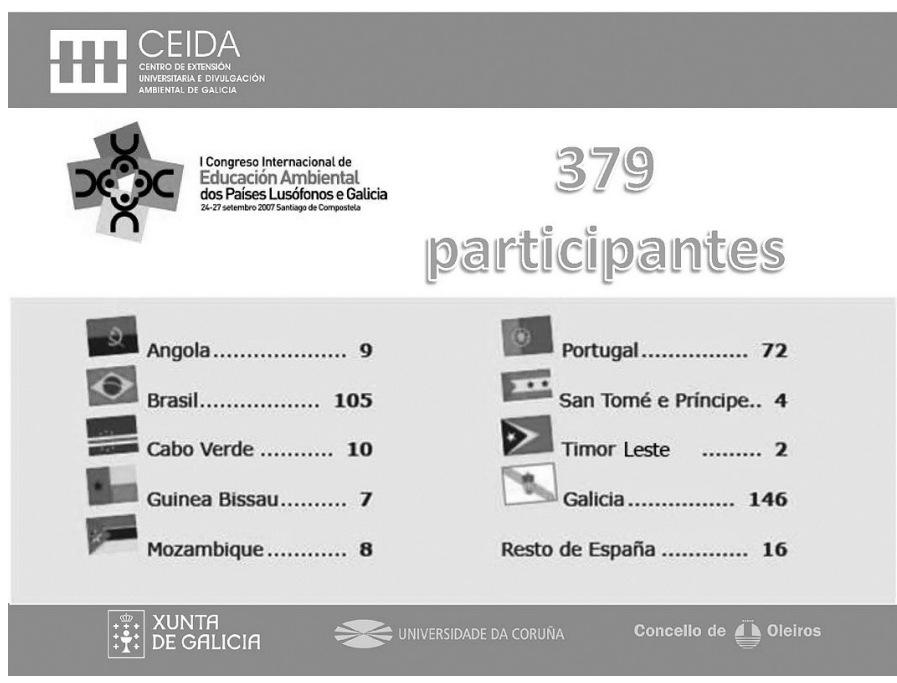


En canto ao Goberno Español, asumiu a maior partida económica da organización do Congreso, a través da Axencia Española de Cooperación Internacional. E no caso galego, a implicación non afectou tan so á Consellería de Medio Ambiente, senón que moitos outros departamentos se sentiron implicados, incluíndo a Vicepresidencia, a través da Secretaria Xeral de Igualdade e políticas de xénero, tamén ás Direccións Xerais de Turismo e a de Xuventude, así como o Consello da Cultura Galega ou a Radio Televisión de Galicia (Foto 5).

A implicación doutras institucións e a súa aportación económica está recollida na Foto 6.

En calquera caso, débese deixar constancia do traballo feito polo CEIDA para implicar a moitas outras entidades tanto públicas como privadas, tanto do ámbito español e do conxunto da lusofonía, para xerar unha rede de parceiros implicados na organización do congreso que fican reflectidos na Foto 7.

Outro dos aspectos que marca un perfil propio do I Congreso Lusófono é o esforzo por incorporar a intelectuais e expertos procedentes doutros ámbitos distintos ao da educación ambiental sensu stricto, nun intento de incorporar perspectivas diferentes á exclusiva do noso campo e de facer un traballo de aproximación entre sectores que comparten un obxectivo común de transformación social ao tempo que serve como un elemento de intercambio e de enriquecemento dos plantexamentos feitos pola nosa disciplina e activismo (CEIDA, 2007). Sirvan como exemplo as mesas celebradas durante o congreso e que incorporaban a politólogos, economistas e activistas políticos.

Algún exemplos destes diálogos:

"O mundo lusófono na globalización"

- Xosé Manuel Beiras. Fundación Galiza Sempre (Galicia)

- Luís Moita. Universidade Autónoma de Lisboa (Portugal)

- Hamilton Pereira. Secretaria de Estado de Articulação Institucional e Cidadanía Ambiental do Ministério do Meio Ambiente (Brasil)

"Medio ambiente, globalización e alterglobalización"

- Carlos Taibo. Universidad Autónoma de Madrid (España)

- Marcos Reigota. Universidade de Sorocaba (Brasil)

- João Paraskeva. Universidade do Minho (Portugal)

En calquera caso, e como conclusión desta primeira parte, non é a Rede Lusófona a que propón a celebración do I Congreso Lusófono, e ademais en 
Foto 5. Institucións galegas e españolas que financiaron o I Congreso.

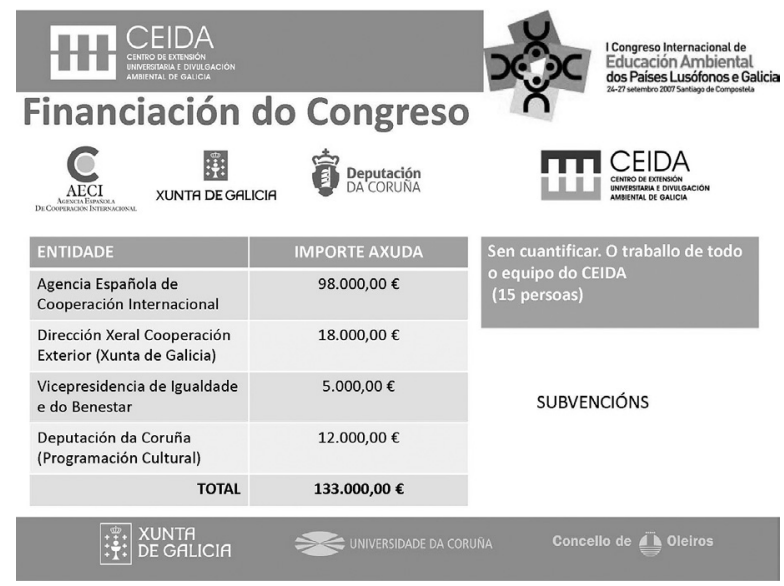

\section{HWCEDA}

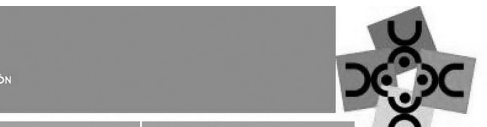

Congreso Internacional de Educación Ambiental dos Países Lusófonos e Galicia

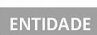

Club Internacional de Prensa

Dirección Xeral de Turismo

Dirección Xeral de Creación e Difusión Cultural

Xacobeo

Turgalicia

Concello de Santiago

El Corte Inglés

Consellos reguladores

Consorcio Turismo A Coruña

Foto Artús

Fundación Caixa Galicia

Consello da Cultura Galega

Sociedade Galega de Educación Ambiental

Grupo de Investigación en Pedagoxia Social e Educación

Ambiental (SEPA) - Universidade de Santiago

Corporación Radio e Televisión de Galicia (CRTVG)

Asociación Galega do Xogo Popular e Tradicional

Punto Radio

TOTAL

\section{MPORTE AXUDA}

$11.989,77 €$

$16.481,33 €$

$13.312,00 €$

$800,00 €$

$500,00 €$

$3.000,00 €$

$3.000,00 €$

$1.000,00 €$

$180,00 €$

$500,00 €$

$1.000,00 €$

$1.500,00 €$

$183,00 €$

$766,23 €$

$20.590,00 €$

$450,00 €$

$1.000,00 €$

$76.252,33 €$

\section{Financiación} do Congreso

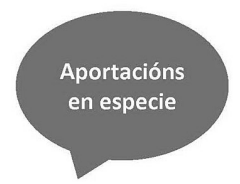

Foto 6. Outros

organismos,

institucións e

empresas que

financiaron 0

I Congreso.

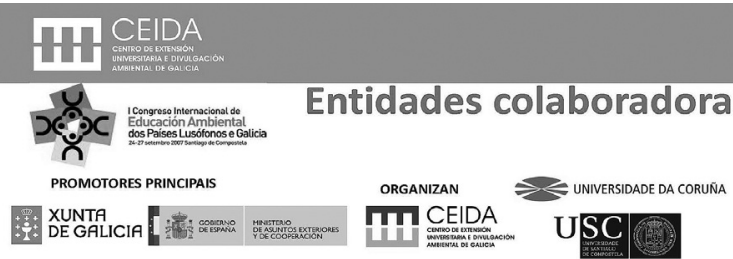

Colaboradores

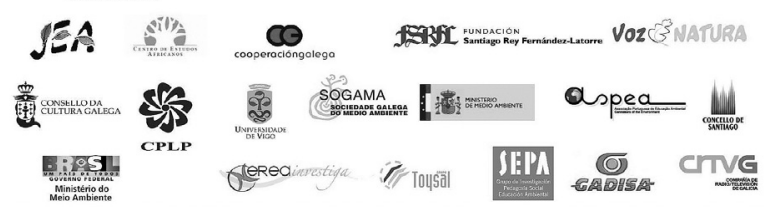

Foto 7. Entidades promotoras e colaboradoras co I Congreso. 
Galicia, senón que son os participantes no Congreso Iberoamericano de Joinville, a proposta da delegación Brasileira, e co apoio do Goberno Español e da Xunta de Galicia, representada polo CEIDA, os que explican a realización deste evento. Do cal todos e todas debemos estar contentos pola súa consolidación posterior e pola súa continuidade ate os nosos días.

\section{Parte II}

As razóns para xustificar que o /l Congreso Lusófono é o celebrado en setembro de 2013 en Cuiabá-Brasil, organizado pola Universidade Federal de Mato Grosso e a Rede Mato-Grossense de Educaçao Ambiental, son para min un enigma. $A$ miña perplexidade ficou reflectida na carta enviada ao Comité Organizador no momento no que se estaba procedendo á divulgación inicial do Congreso, no que, como Director do CEIDA e Presidente do Comité Organizador do I Congreso Lusófono de Educación Ambiental, poño de manifesto a descortesía inicial de non ter convidado ao CEIDA, e a min como responsable principal da celebración do I Congreso, a formar parte da comisión organizadora, despois de todo o traballo desenvolvido con posterioridade ao I Congreso para darlle continuidade.

Neste escrito, poño novamente de manifesto que a celebración do I Congreso de Educación Ambiental dos Países Lusófonos e a Galicia foi unha proposta unánime do VI Congreso Iberoamericano de Educación Ambiental. Foi nese contexto e co apoio fundamental da delegación brasileira e especialmente do Marcos Sorrentino e da Raquel Trajber,

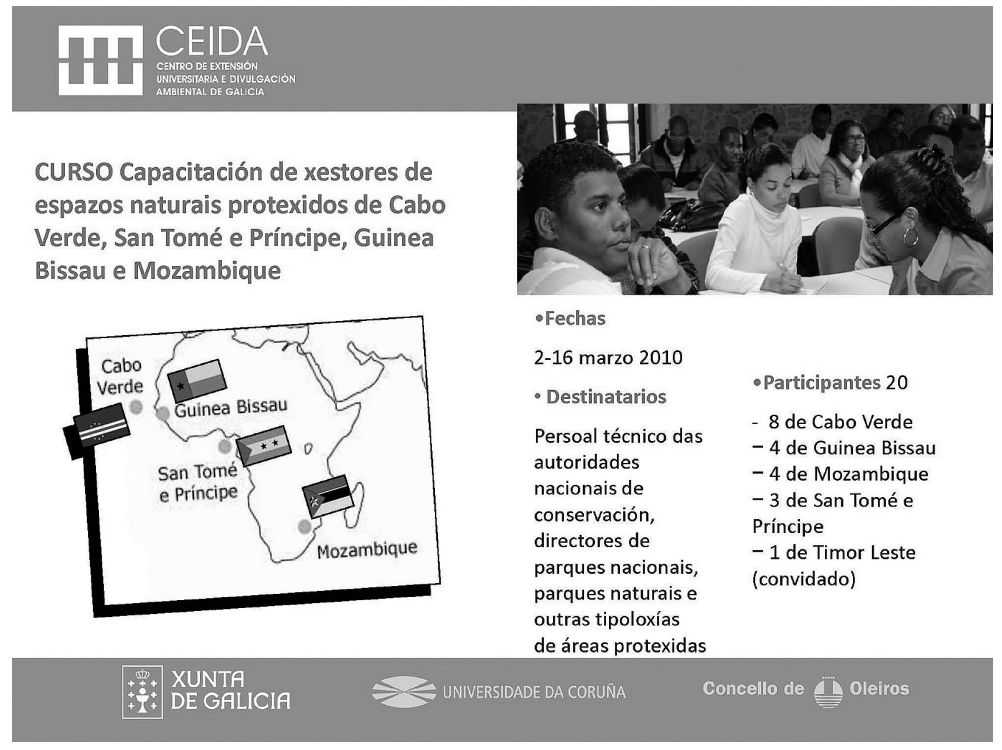

Foto 8. Participantes do Curso de Capacitación de xestores de ENP de Cabo Verde, São Tomé e Príncipe, Guiné Bissau e Mozambique. 
que se fai a proposta de que a Galicia organizara ese congreso, mandato que trasladei ao goberno da Galicia e que felizmente fomos capaces de executar e que tivo continuidade nos anos seguintes coa visita de representantes de todos os países lusófonos para participar no proceso formativo organizado polo CEIDA no que, por primeira vez se lle da formación aos xestores de conservación e das áreas protexidas dos países Iusófonos (Carlos VALES, 2010) (Foto 8).

Esta formación fíxose en colaboración con Organismo Autónomo Parques Nacionais da España, a Xunta de Galicia, - Instituto Jane Goodall, diversas Universidades españolas además da colaboración de Brasil, a través da Universidade de Sao Paulo e Portugal, a través do Instituto de Estudos Africanos. Estas xornadas formativas culminaron na creación da Rede Pardela, un escenario de intercambio de experiencias e adquisición de destrezas na xestión das áreas naturais protexidas no mundo, incluíndo especialmente a todos os países da CPLP e a España, con especial relevancia en Galicia (Foto 9).

Ademais é obrigado resaltar que no ano 2010 xa se celebrara en Cabo Verde, na cidade da Praia, o II Congreso Internacional de Educación Ambiental en Territorios Lusófonos (CEIDA, 2011:95), no que si estaban presentes o Presidente e a Vicepresidenta do I Congreso na Galiza.
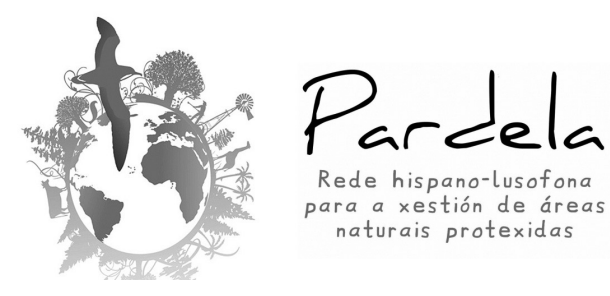

Rede hispano-lusofona para a xestión de áreas naturais protexidas

Foto 9. Logotipo da Rede Pardela

O congreso celebrado na cidade da Praia, sí contaba co apoio institucional do Goberno caboverdiano. Foi un congreso onde houbo participación relevante de Brasil, Angola, Portugal e a Galiza (ver cadro adxunto), e penso que con todo o dereito debe ser recollido na historia dos congresos lusófonos de educación ambiental (Foto 10).

Felizmente, desde o III Congreso celebrado en Murtosa, Aveiro (Portugal) en xullo de 2015, o apoio institucional moi importante aínda que suficientemente fraco como para que toda a equipa do CEIDA tivese que desprazarse ate 0 lugar do congreso para contribuír co seu esforzo ao éxito do mesmo. En calquera caso, a historia posterior demostra a consolidación diante dos gobernos dos nosos diferentes países dos congresos lusófonos e, en particular, da Rede Luso como o referente capaz de marcar unha liña referencial para a educación ambiental no noso espazo xeográfico, cultural e linguístico compartillado na súa diversidade. 


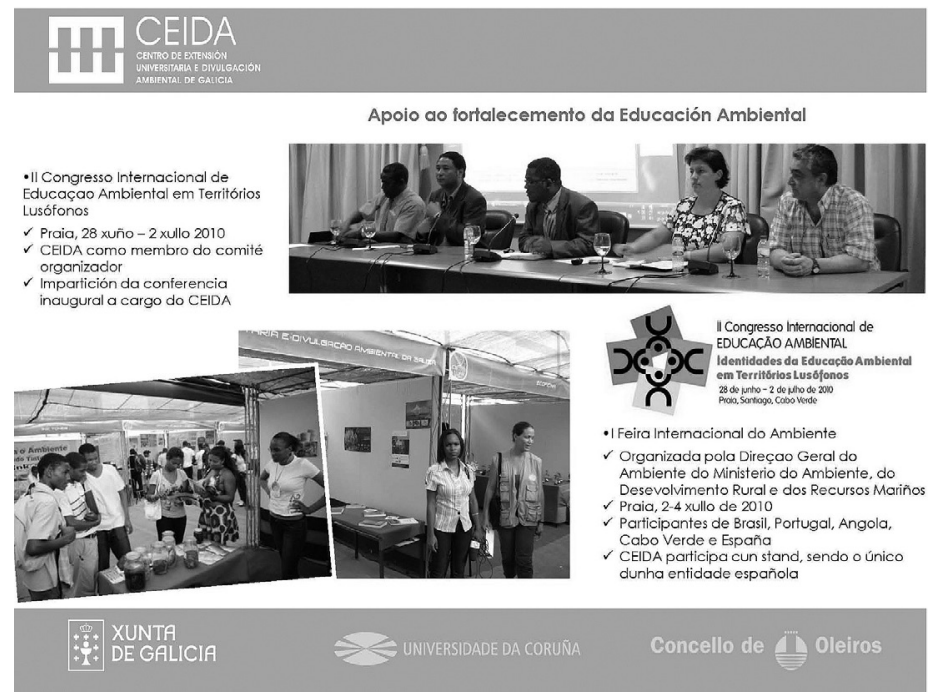

Foto 10. II Congreso

Internacional de

Educación Ambiental en

Territorios Lusófonos

\section{Reflexións finais}

- Os congresos de educación ambiental no ámbito da CPLP, incluída a Galiza, teñense convertido nunha formidable ferramenta de intervención institucional.

- A reflexión intelectual é importantísima, imprescindible, pero ten que servir para construír alianzas para transformar o mundo, alianzas na sociedade civil, no ámbito institucional, a ser posible en ámbolos dous.

- Compre fuxir da tentación de converter os nosos congresos nun espazo fundamentalmente académico e non nun instrumento de creación de intelixencia colectiva e de apoio a intervención socioambiental.

- A educación ambiental é un instrumento para facer fronte á crise ambiental. E iso significa, antes que nada, activismo social e influencia institucional.

- Iso implica, por suposto, a importancia da reflexion intelectual e académica como elemento imprescindible para construír o armazón dos nosos discursos.

- Deberíamos aproveitar os nosos congresos para promover alianzas con outros sectores que compartillan unha vision do mundo crítica co actual modelo de produción e consumo.

- O obxectivo máis importante dos Congresos da Comunidade de Países de Lingua Oficial Portuguesa debera ser fortalecer o activismo social proambiental, asi como conseguir influir sobre as institucións para que o ambiente teña maior peso nas súas políticas. 


\section{Referencias bibliográficas}

CEIDA (2011). Memoria de actividades. CEIDA 2001-2011. Ourense: CEIDA. [http://www. ceida.org/sites/default/files/adxuntos-publicaciones/memoriaceida2001-2011.pdf]

CEIDA (2007). I Congreso Internacional de Educación Ambiental dos Países Lusófonos e Galicia. Comunicacións. Oleiros: CEIDA. (CD-Rom ISBN-13 978-84-690-7996-6).

CEIDA (2005). Memoria de actividades. CEIDA 2001-2005. A Coruña: CEIDA. [http://www. ceida.org/sites/default/files/adxuntos-publicaciones/memoriaactividades20012005_0. pdf]

VALES, Carlos (coord.) (2010). Manual de Gestión de Áreas Protegidas para los Países Lusófonos. A Coruña: CEIDA

VALES, Carlos (2006). CEIDA: Un centro de refe-. rencia para a Educación Ambiental en Galicia, ambientalMENTE sustentable, $\mathrm{n}$. 1-2, pp. 265-279.

VV.AA (2010). Manual de gestión de áreas protegidas. Oleiros: CEIDA. 